Original Research Article

\title{
Comparison of efficacy of difluprednate $0.05 \%$ vs dexamethasone $0.1 \%$ eye drops in inflammation associated with small incision cataract surgery
}

\author{
Preet Sood*, Manmohan Bhanot
}

Department of Pharmacology,

Sri Guru Ram Dass Institute of Medical sciences and Research, Amritsar, Punjab, India

\section{Received: 01 March 2017 \\ Revised: 05 May 2017 \\ Accepted: 08 May 2017 \\ *Correspondence to: \\ Dr. Preet Sood, \\ Email: preetsood2222@ \\ gmail.com}

Copyright: (C) the author(s), publisher and licensee Medip Academy. This is an openaccess article distributed under the terms of the Creative Commons Attribution NonCommercial License, which permits unrestricted noncommercial use, distribution, and reproduction in any medium, provided the original work is properly cited.

\begin{abstract}
Background: Post operative ocular inflammation is a common happening after any type of surgery. Corticosteroids have been used to treat ocular inflammation however, they carry a risk of side effects, particularily an increase in IOP. A newer steroid, difluprednate is found to be safe than dexamethasone.

Methods: Total 120 patient undergoing small incision cataract surgery was enrolled in this prospective, randomized and single blind (investigator masked) parallel study. Either of the two eye drops (dexamethasone/difluprednate) were prescribed post operatively. Patients were examined on postoperative day 1, 7, 14 and 28 for - Intraocular pressure, anterior chamber cells and flare with slit lamp examination.

Results: As difluprednate was found effective in reducing pain in $62 \%$ of the patients on day 3 as compared to dexamethasone group on day 7 i.e. $76 \%$ of the patients. Both the drugs has no significant effect on the intraocular pressure.

Conclusions: Patients in difluprednate preparation have shown good compliance owing to the lesser frequency of drug administration. Better tolerability because of the emulsion form is also an encouraging factor. The only discouraging factor for difluprednate preparation is the cost. As the frequency of drug administration as compared to dexamethasone is less (QID), it is compromised a bit.
\end{abstract}

Keywords: Difluprednate, Dexamethasone, Post ocular inflammation, Small incision cataract surgery

\section{INTRODUCTION}

Post operative ocular inflammation is a common happening after any type of surgery. Cataract surgery is an invasive procedure that requires incision and cutting of ocular tissue as well as considerable intraocular tissue manipulation. Surgical manipulation leads to the disruption of the blood aqueous barrier, resulting in intraocular inflammation. Postoperative inflammation can lead to complications such as pain, discomfort, photophobia, corneal edema, posterior synechiae, elevation in IOP and cystoid macular edema. ${ }^{1}$ Topical corticosteroids are a very effective treatment for postoperative ocular inflammation. Corticosteroids inhibit the release of arachidonic acid from cell membrane phospholipids and prevent the formation of both leukotrienes and prostaglandins, thus disrupting the inflammatory cascade., ${ }^{2,3}$ Corticosteroids have been used to treat ocular inflammation however; they carry a risk of side effects, particularily an increase in IOP. If left untreated, could lead to glaucoma. ${ }^{4}$ The postoperative inflammation can be assessed by monitoring anterior chamber signs such as, cell grade, flare grade with slit lamp examination.

To counteract it a little bit of steroid and small amount of antibiotic cover isalso it's the individual decision of the 
surgeon what to prescribe depending upon its own experience.

In ocular surgery, dexamethasone eye drops are commonly used. ${ }^{5}$ Although it is effective but better drugs like Difluprednate are available. It is promoted for increasing the compliance by reducing frequency of drops, a more potent and more comfortable effect. ${ }^{6}$

Difluprednate is an optical steroid emulsion eye drop. Being an emulsion it is considered as prodrug. It rapidly penetrates the corneal epithelium where it quickly deacetylates to difluoroprednisolone butyrate (DFPB), the active metabolite. This DFPB has strong corticosteroid receptor agonist activity, and in clinical trials has been demonstrated to be more powerful. ${ }^{7}$

In the immediate postoperative period, topical corticosteroids and antibiotic combined eye drops are effective. It is expected to improve patient compliance from an economical standpoint, the combination product reduces medication cost since single bottle is required as compared to two separate bottles. ${ }^{3}$ A fixed combination eye preparation, So not only help in cutting costs but improve compliance of patient in dosing and application. ${ }^{8}$

In our study combination of moxifloxacin with dexamethasone is compared with moxifloxacin with difluprednate eye drops.

The study was carried out at Sri Guru Ramdass Institute of Medical Sciences and Research in the Department of Ophthalmolgy and Pharmacology from June to December 2016.

\section{METHODS}

It was a prospective, randomized, singleblind (investigator masked) parallel designed study. It was being conducted in post small incision cataract surgery patients. Irrespective of gender total $120(n=60$ each $)$ patients will be enrolled in two study groups.

After randomization patients will be allocated either in group A (Difluprednate $0.05 \% \mathrm{w} / \mathrm{v}$ with moxifloxacin $0.5 \mathrm{w} / \mathrm{v}$ ) or in group B (Dexamethasone $0.5 \% \mathrm{w} / \mathrm{v}$ with moxifloxacin $0.5 \mathrm{w} / \mathrm{v}$ ) eye drops. Pre-structured Prescriptions (A or B) will be given by an attendant. Patients were examined on postoperative day 1, 7, 14 and 28 for - Intraocular pressure, Anterior chamber cells and flare with slit lamp examination (graded according to the standardization of uveitis nomenclature), Best corrected visual acuity (BCVA) on day 28 .

Informed written consent will be obtained from the patient or the attendant of the patient.

\section{Inclusion criteria}

Patients aged $\geq 30$ years with non-complicated cataract.

\section{Exclusion criteria}

Uncontrolled glaucoma, on steroids, pregnant and diabetic mellitus, H/O of allergy to steroids, inflammatory conditions like iridocyclitis, darocyctitis, fungal and viral infections

Table 1: The schedule for drug administration.

\begin{tabular}{|lll|}
\hline $\begin{array}{l}\text { Time interval } \\
\text { (in weeks) }\end{array}$ & $\begin{array}{l}\text { Group A } \\
\text { (Difluprednate) }\end{array}$ & $\begin{array}{l}\text { Group B } \\
\text { Dexamethasone) }\end{array}$ \\
\hline $1^{\text {st }}$ & 4 times a day & 6 times a day \\
\hline $2^{\text {nd }}$ & 4 & 5 \\
\hline $3^{\text {rd }}$ & 2 & 4 \\
\hline $4^{\text {th }}$ & 2 & 3 \\
\hline $5^{\text {th }}$ & 1 & 2 \\
\hline $6^{\text {th }}$ & 1 & 1 \\
\hline
\end{tabular}

Patients had been examined post operatively on day $1,5,7,14,28$. At each visit, patients were examined for sign of infection, inflammation and ocular pain. Best corrected visual acuity and intraocular pressure measured and recorded.

Grading scheme was achieved for standardization of grading anterior chamber cells and flare. The first international Workshop on the Standardization of Uveitis Nomenclature (SUN) was held in 2004 to standardize some aspects of uveitis, including classification criteria, inflammation grading scheme, and evaluation of outcomes. ${ }^{9}$ AC (anterior chamber) inflammation, major criterion of effectiveness, were evaluated based on number of cells per high power field measure using narrowest $(0.5$ at height of $8 \mathrm{~mm})$ slit beam of lamp and recorded as sun classification:

1. Anterior Chamber Cell Grading by SUN: Grade cells in field $0<51+6-152+16-253+26-504+>50$

2. Anterior chamber flare grading by SUN: Grade descriptors- 0 None, $1+$ faint, $2+$ moderate (iris and lens detail clear), 3+ marked (iris and lens detail hazy), 4+ intense (fibrin or plastic aqueous)

3. Ocular Pain was assessed by Visual Analogue Scale (VAS)

4. Intraocular pressure was measured on day 28 with applantion tonometer.

Table 2: Visual analogue scale.

\begin{tabular}{|ll|}
\hline Absent & 0 \\
\hline Mild & 1 \\
\hline Moderate & 2 \\
\hline Severe & 3 \\
\hline Extreme & 4 \\
\hline
\end{tabular}

\section{RESULTS}

Changes in the various parameters recorded re as follows: 


\section{Effect on anterior cell and flare}

The reduction in aqueous cell (at day 3 ) and aqueous flare (at day 7) is early with difluprednate.

Table 3: Comparison of anterior cell count reduction.

\begin{tabular}{|lllll|}
\hline Group & $\mathbf{1}^{\text {st }}$ day & $\mathbf{3}^{\text {rd }} \mathbf{d a y}$ & $\mathbf{5}^{\text {th }}$ day & $\mathbf{7}^{\text {th }}$ day \\
\hline A (MDx) & 0 & $50.66 \%$ & $92.07 \%$ & $100 \%$ \\
\hline B (MDf) & 0 & $63.46 \%$ & $95.13 \%$ & $100 \%$ \\
\hline
\end{tabular}

Table 4: Comparison of anterior flare reduction.

\begin{tabular}{|lllll|}
\hline Group & $\mathbf{1}^{\text {st }}$ day & $\mathbf{3}^{\text {rd }}$ day & $\mathbf{5}^{\text {th }}$ day & $7^{\text {th }}$ day \\
\hline A (MDx) & 2.54 & 1.27 & 0.22 & 0 \\
\hline B (MDf) & 2.67 & 1.07 & 0.08 & 0 \\
\hline
\end{tabular}

\section{Effect on pain}

Difluprednate was found effective in reducing pain in $62 \%$ of the patients on day 3. Similar effect was found in dexamethasone group on day 7 i.e. $76 \%$ of the patients.

Effect on Intraocular pressure- both the drugs has no significant effect on the intraocular pressure. Three $(3.7 \%)$ subjects in the difluprednate group had a clinically significant increase in IOP that resolved either spontaneously or with appropriate medical treatment.

\section{DISCUSSION}

Cataract surgery has become one of the safest, most successful and most frequently performed Surgeries. Advances in techniques and equipment have led to a dramatic increase in the popularity of phacoemulsification with increased safety and accuracy.

The role of steroids in postoperative period is undisputable.

In 1950, Gordon and Mclean introduced steroids in ocular therapy and in 1951 ocular formulations arrived. In 1959 dexamethasone $0.1 \%$ eye drops were introduced to treat ocular inflammation. ${ }^{10}$ After 1973, difluprednate is first steroid to be approved by FDA in 2008.

A study by smith et al, using a wide range of clinical indicators, this study showed that administration of difluprednate 2 times daily starting 24 hours before surgery when compared with placebo, was highly effective for the management of postoperative ocular inflammation and pain. Clinical resolution of $\mathrm{AC}$ inflammation (based on cells and flare) on day 14 was demonstrated, a difference both clinically meaningful and highly statistically significant $(\mathrm{P}=0.0006)$. Moreover, this treatment benefit was observed as early as day 7 and was sustained through day 28. Ocular pain and discomfort was also significantly reduced in the difluprednate group $(\mathrm{P}<0.001$ on day 14$)$; this treatment benefit was observed early (day 3/4) and sustained through day 28 .

This is particulary impressive, since no other antiinflammatory agents were used in this trial. The rate of IOP increase is similar to that observed when difluprednate is dosed 4 times daily and similar to other topical steroids, including prednisolone and rimexolone, in similar clinical settings. ${ }^{11}$

In the present study, moxifloxacin-dexamethasone and moxifloxacin difluprednate are found effective in post operative inflammation. The results are comparable with other studies, in which difluprednate was compared with dexamethasone in the phacoemulsification patients. ${ }^{12,13}$

In another study, effect on intraocular pressure from topical difluprednate was studied. Difluprednate $0.05 \%$ has a reported associated increase in intraocular pressure (IOP) in $3 \%$ of patients. ${ }^{14}$ But in our study both the drugs have equal effect on intraocular pressure. This may be due to the shorter duration of the study and small sample size. And concluded clinicians need to be aware of the potential risk for significant and potentially rapid onset of IOP increase with this medication and manage patients accordingly.

Some studies indicate that compliance with difluprednate is indicated to be better as it has QID dosage compared to six times of dexamethasone.

Patients in difluprednate preparation have shown good compliance owing to the lesser frequency of drug administration. Better tolerability because of the emulsion form is also an encouraging factor. The only discouragingfactor for difluprednate preparation is its cost. As the frequency of drug administration as compared to dexamethasone is less (QID), it is compromised a bit.

Funding: No funding sources Conflict of interest: None declared

Ethical approval: The study was approved by the Institutional Ethics Committee

\section{REFERENCES}

1. Simone JN, Whitacre MM. Effects of antiinflammatory drugs following cataract extraction. Curr Opin Ophthalmol. 2001;12:63-7.

2. Rhen T, Cidlowski JA. Anti inflammatory action of glucocorticoids: new mechanisms for old drugs. $\mathrm{N}$ Engl J Med. 2005;353:1711-23.

3. McColgin AZ, Heier JS. Control of intraocular inflammation associated with cataract surgery. Curr Opin Ophthalmol. 2000;11:3-6.

4. Becker B. Intraocular pressure response to topical corticosteroids. Invest Ophthalmol. 1965;4:198-205.

5. Campos M, Mariana Á, Wallau A, Muccioli C, Höfling-Lima AL, Belfort R. Efficacy and 
tolerability of a fixed-dose moxifloxacindexamethasone formulation for topical prophylaxis in LASIK: a comparative, double-masked clinical trial Clin Ophthalmol. 2008 Jun;2(2):331-8.

6. Cable MM. Intraocular pressure spikes using difluprednate $0.05 \%$ for postoperative cataract inflammation. Assoc Res Vis Ophthalmol Ann Meet Abstr. 2010;51:198413.

7. Stephen S, Douglas L, Peace J, McLeod K, Crockett RS, Vogel R. Difluprednate ophthalmic emulsion $0.05 \%$ (Durezol) administered two times daily for managing ocular inflammation and pain following cataract surgery. Clin Ophthalmol. 2010;4:983-9916.

8. Freitas L, Soriano E, Muccioli C, Hofling-Lima AL, Belfort R. Efficacy and tolerability of a combined moxifloxacin/ dexamethasone formulation for topical prophylaxis and reduction of inflammation in phacoemulsification. A comparative double masked clinical trial. Current Medical Research and opinion. 2008;23(12):3123-30.

9. Jabs DA, Nussenblatt RB, Rosenbaum JT. Standardization of Uveitis Nomenclature (SUN) working group: Standardization of Uveitis Nomenclature (SUN) for reporting clinical data. Results of the first international workshop, Am J Ophthalmol. 2005;140;509-16.
10. Gordon DM. Use of dexamethasone in eye. The Journal of the American Medical Association. 1960;172(4):311-12.

11. Abelson MB, Butrus S. Corticosteroids in ophthalmic practice. Albert and Jakobiec's; Principles and Practice of ophthalmology. $3^{\text {rd }}$ Ed. 2008;23:249-250.

12. Bharolia AC, Raja AH. A Retrospective Study to Compare Moxifloxacin-Dexamethasone and Moxifloxacin-Difluprednate Eye Drops In Post Cataract Surgery. International journal of scientific research. 2016;5(4).

13. Chaudhary N, Arora I, Gupta DC, Gupta CP. Comparison of efficacy and safety of dexamethasone $0.1 \%$ and difluprednate $0.05 \%$ in the management of ocular inflammation after phacoemulsification Journal of medical and dental sciences. 2015;4(74):12899-903.

14. Meehan K, Vollmer L, Sowka J. Intraocular pressure elevation from topical difluprednate use. Optometry. 2010;81(12):658-62.

Cite this article as: Sood $\mathrm{P}$, Bhanot M. Comparison of efficacy of difluprednate $0.05 \%$ vs dexamethasone $0.1 \%$ eye drops in inflammation associated with small incision cataract surgery. Int J Basic Clin Pharmacol 2017;6:1526-9. 